\title{
Gestão de Custos Interorganizacionais: Um Estudo Bibliométrico
}

\author{
Interorganizational Cost Management: A Bibliometric Study
}

\author{
Rafael Araújo Sousa Farias \\ Mestre em Contabilidade pela Universidade Federal de Santa Catarina \\ Centro Socioeconômico, Bloco F \\ Universidade Federal de Santa Catarina - Florianópolis, SC \\ CEP: 88040-970 \\ E-mail: farias-rafael@ hotmail.com \\ Telefone: (61) 8354-3283
}

\author{
Valdirene Gasparetto \\ Doutora em Engenharia de Produção pela Universidade Federal de Santa Catarina \\ Centro Socioeconômico, Bloco F \\ Universidade Federal de Santa Catarina - Florianópolis, SC \\ CEP: 88040-970 \\ E-mail: valdirene.gasparetto@ufsc.br \\ Telefone: (48) 8404-2416
}

\begin{abstract}
Resumo
O objetivo deste artigo é identificar o perfil da produção científica, no Brasil e internacionalmente, acerca da Gestão de Custos Interorganizacionais (GCI). Este estudo se apresenta na forma de uma pesquisa bibliométrica, embasada em pesquisa bibliográfica, por meio da análise de trabalhos publicados em eventos nacionais e em repositórios eletrônicos. Foram identificados 55 trabalhos que discorrem sobre a GCI e uma baixa quantidade de autores que publicaram (73 autores), sendo que 28 são nacionais e 45 internacionais. Cooper e Slagmulder são os autores internacionais mais produtivos enquanto Souza e Rocha são os autores com maior número de publicações no Brasil. Sociogramas demonstraram as relações existentes entre os autores dos trabalhos, evidenciando a não ocorrência de relações entre os autores brasileiros e internacionais e poucas redes entre os autores, de um modo geral. A análise epistemológica dos artigos publicados em periódicos demonstrou: a) predominância de citação de artigos publicados em periódicos $(74,7 \%)$; b) estudos de campo como principal estratégia metodológica $(50 \%)$; c) predominância no uso de conceitos - poucos trabalhos utilizaram teorias - como plano de fundo das pesquisas $(97,1 \%)$; e d) predominância de paradigma funcionalista $(94,1 \%)$. Ao longo dos anos se observou tendência de crescimento no número de publicações sobre o tema, principalmente no Brasil.
\end{abstract}

Palavras-chave: Gestão de Custos Interorganizacionais; Interorganizational Cost Management; Bibliometria; Epistemologia, Análise de conteúdo. 


\begin{abstract}
The objective of this study is to provide an overview of scientific publications on Interorganizational Cost Management (IOCM), both in Brazil and at the international level. The research at hand is carried out by way of a bibliometric study, with base in bibliographic research, employing an analysis of works published in both Brazilian conferences and online databases. Fifty-five studies that broach IOCM were found. The results also showed a low number of authors working in the same field (73 in total), of which 28 were Brazilian and 45 from other countries. Cooper and Slagmulder were found to be the most prolific of the international authors, while Souza and Rocha those with the greatest number of publications in Brazil. Graphic representation using sociograms demonstrated the relationships existing between the authors of the works in question, displaying the non-relationship between Brazilian and international authors, and few links between the authors, in general. Epistemological analysis of the works published in journals showed the following: a) the predominance of citing articles published in journals $(74,7 \%)$; b) field studies as the main methodological strategy employed $(50 \%)$; c) the overall tendency to use concepts and definitions as the backdrop of the study $(97,1 \%)$; and d) the dominance of the functionalist paradigm $(94,1 \%)$. Finally, an increase in the number of publications on the topic was shown over the years in question, particularly in Brazil.
\end{abstract}

Keywords: Interorganizational Cost Management; Bibliometrics; Epistemology; Content Analysis.

\title{
1 Introdução
}

Atualmente, as distâncias entre as organizações estão sendo reduzidas e as relações com fornecedores e clientes, antes acanhadas, vêm se estreitando, forçando as empresas a um novo modo de agir. Hoje a concorrência pelos mercados se dá entre cadeias de suprimento e não mais entre empresas, isoladamente, mesmo que grande parte dos elementos das cadeias concorrentes seja comum e compartilhada (CORRÊA, 2014).

A percepção de que as empresas necessitam arquitetar relações estratégicas com os membros de suas cadeias de suprimento é relativamente nova, sendo originalmente introduzida por consultores no início dos anos 1980 (LAMBERT; COOPER 2000). Coad e Scapens (2006) afirmam que nenhuma organização é uma ilha e que todas operam em rede com fornecedores, clientes, parceiros de aliança, financiadores e organismos do governo. A partir desse contexto surge, na área da gestão estratégica dos custos, a Gestão de Custos Interorganizacionais (GCI) ou Interorganizational Cost Management (IOCM), que busca a redução dos custos para a cadeia como um todo, criando vantagem competitiva perante as cadeias concorrentes.

Gestão de Custos Interorganizacionais é uma abordagem estruturada para a coordenação das atividades das empresas em uma rede de fornecimento, para que os custos totais da rede sejam reduzidos (COOPER; SLAGMULDER, 1999). Souza e Rocha (2009, p. 25) definem GCI como "um processo cooperativo de gerenciamento de custos que inclui outras organizações de uma cadeia de valor além da própria empresa".

Apesar de se mostrar recente na literatura, é possível constatar que o estudo sobre GCI e inter-relacionamento entre as organizações é de crescente interesse de pesquisadores como, por exemplo, Porter, Shank e Govindarajan, e Cooper e Slagmulder (SOUZA; ROCHA 2009). Faria et al. (2010) corroboram afirmando que no ano de 2010, em âmbito nacional, era possível identificar uma quantidade crescente de pesquisas sobre o tema. 
Hesford et al. (2007) explicam que desde o início da década de 1980 vem ocorrendo significativa expansão no número de pesquisas em contabilidade gerencial, devido, principalmente, ao surgimento de novos tópicos de pesquisa e ao crescente número de periódicos e eventos dedicados ao tema. No Brasil, segundo Nascimento, Junqueira e Martins (2010), percebe-se uma mudança significativa a partir da primeira década do século XXI, devido ao surgimento de novos programas de pós-graduação e ao aumento do número de eventos e revistas científicas dedicadas às questões relacionadas à contabilidade.

Diante do crescente interesse pelo tema, esta pesquisa pretende responder a seguinte questão: qual é o perfil da produção científica acerca da GCI? Nesse sentido, o estudo tem como objetivo geral identificar o perfil da produção científica em Gestão de Custos Interorganizacionais. Especificamente, pretende: i) verificar a produção científica brasileira e internacional sobre GCI; ii) identificar se a tendência de aumento no número de trabalhos publicados nesse campo de conhecimento, como mencionado por Faria et al. (2010), se confirmou; iii) identificar como ocorreram as relações entre os autores, no Brasil e internacionalmente; e iv) analisar o conteúdo e as características epistemológicas dos artigos publicados em periódicos. Trabalhos que desenvolvem estudos sobre o perfil da produção e das fundações epistemológicas acerca de um tema específico dão suporte ao desenvolvimento do conhecimento (MEIRELLES; GONÇALVES, 2005), além de auxiliar no debate das diferenças epistemológicas existentes entre as pesquisas em ciências sociais (DIAS; BIROCHI; DEAMBROSIS; DAROSI; MATOS, 2013).

\section{Referencial Teórico}

\subsection{Contextualização da GCI}

A gestão de uma organização requer atenção para além do ambiente interno. Shank e Govindarajan (1993, p. 59) explicam que "na estrutura da gestão estratégica de custos, gerenciar custos eficazmente exige um enfoque amplo, externo à empresa". Kulmala, Kajüter e Valkokari (2007) afirmam que, na tentativa de identificar e explorar novas oportunidades de redução de custos, muitas empresas têm estendido o foco de suas atividades de gestão de custos para além das suas fronteiras organizacionais, mas Kulmala, Paranko e Uusi-Rauva (2002) constatam que a maioria das práticas de gestão tem o seu alcance restrito aos limites da empresa, tornando difícil tirar proveito das sinergias que levam a redução de custos na cadeia de suprimento.

Souza e Rocha (2009) explicam que informações externas à companhia estão sendo cada vez mais requisitadas pelos gestores. A gestão das relações com os fornecedores se torna ainda mais importante quando há uma situação de interdependência, que ocorre quando determinada empresa não apresenta condições de reger todos os fatores necessários para concluir determinado produto ou para obter certo resultado (PFEFFER; SALANCIK, 1978).

Porter (1989, p. 44) aponta que a produção de um bem passa por diversas etapas interligadas que se influenciam mutuamente, sendo categórico ao dizer que "a cadeia de valores não é uma coleção de atividades independentes, e sim um sistema de atividades interdependentes". O relacionamento entre as organizações é campo para aplicação da GCI, já que é de seu interesse, por meio da redução de custos, criar vantagens para toda a cadeia de suprimento.

A GCI busca reduzir custos na relação fornecedor-cliente, mas almeja também uma gestão mais "inteligente", para que as relações cooperadas da cadeia sejam mais eficientes perante as cadeias concorrentes (COOPER; SLAGMULDER, 1999). Amato Neto (2000) demonstra vantagens ao aplicar a gestão de custos em uma cadeia ao invés de aplicá-la em uma empresa isoladamente, citando, entre outras, a possibilidade de haver combinação de competências, utilização de know-how das outras empresas, divisão do ônus ao realizar 
pesquisas tecnológicas, divisão dos riscos e custos de explorar novas oportunidades, compartilhamento de recursos e fortalecimento do poder de compra. Souza e Rocha (2009, p. 2) reconhecem que o "crescimento de alianças estratégicas e de outros enfoques de cooperação nos negócios têm conduzido a resultados espetaculares". Um dos fatores de sucesso da cooperação está na troca de informações entre as empresas. Uzzi (1996) concluiu que as empresas tendem a trocar informações estratégicas prioritariamente com aquelas que fazem parte de sua rede de cooperação.

Coad e Cullen (2006) afirmam que atualmente tanto as organizações do setor público como as do setor privado se envolvem em novas formas de cooperação umas com as outras. Essa indefinição acerca das fronteiras das entidades eleva a importância da gestão dos custos interorganizacionais.

Com essa nova maneira de se relacionar, surgem temas que merecem maior atenção, como por exemplo, a decisão de comprar ou produzir determinado bem ou serviço. Outro ponto que emerge é a questão do arranjo institucional (COAD; CULLEN, 2006). Segundo Garcias (1999), citado por Facci (2011, p. 25), "a partir de um determinado arranjo institucional que define as regras do jogo e o comportamento dos indivíduos, e que influencia no desenho das estruturas e no funcionamento dos agentes, será adotada a forma organizacional ou a estrutura de governança mais eficiente".

Como há uma tendência de que as empresas "caminhem" de mãos dadas e que vislumbrem o futuro juntas, é necessária a utilização de instrumentos que mensurem o valor das transações que ocorram entre as organizações. Estudos apontam (COOPER; SLAGMULDER, 1999; KAJÜTER; KULMALA， 2005; KULMALA; KAJÜTER; VALKOKARIA, 2007) que as empresas estão, em conjunto, adotando técnicas de gestão como, por exemplo, a análise completa da cadeia de valor, medição de desempenho da relação, criação de um orçamento conjunto para a relação interorganizacional, avaliação do investimento na transação, entre outras.

Nesses esforços conjuntos pode haver receio em compartilhar informações internas da empresa e informações acerca da estrutura do custo do produto como, por exemplo, a margem de lucro do mesmo (DEKKER, 2003; KAJÜTER; KULMALA, 2005; HOFFJAN; KRUSE, 2006). Nesse sentido, para tentar evitar esse desconforto, algumas precauções devem ser adotadas para assegurar a integridade da empresa que aspira entrar em uma rede de cooperação com outras. Abbade (2005) adverte que as empresas devem precaver-se de ações oportunistas de outras, para isso, entre outras atitudes, devem determinar claramente qual será a contribuição de cada um dos parceiros na GCI, proteger seus recursos estratégicos e conhecer a história de possíveis parceiros. Kulmala e Kajüter (2005) apontam a abertura dos livros contábeis como fator essencial para o sucesso da GCI.

Ainda na direção dos cuidados a serem tomados antes de partir para a implantação da GCI, deve-se fazer um estudo e averiguar se existem os fatores que condicionam a aplicação do método, sendo um desses fatores, o tipo de relacionamento que existe entre os membros da rede. Segundo Cooper e Slagmulder (2003a), há três tipos de redes de relacionamento possíveis, sendo eles, tirania, oligarquia e democracia, o que remete às características de governança colaborativa na cadeia, que precisam ser consideradas.

Nesse sentido, quando as relações entre as organizações se dão via mercado (WILLIAMSON, 1989), é comum o estabelecimento de relacionamentos ganha-perde, em que uma organização barganha melhores preços com fornecedores e clientes, criando certa disputa entre eles, indo, desse modo, na contramão da GCI. Porter (2004) afirma que a negociação entre as empresas é uma maneira de buscar a diminuição dos preços, já que a empresa compradora tende a colocar os fornecedores uns contra os outros. Essa é uma das explicações para, muitas vezes, as empresas não quererem compartilhar informações de seus produtos. Entretanto, na visão da GCI, quanto mais informação compartilhada, melhor será o 
desempenho das partes que trocam conhecimento, já que a informação é necessária para o bom uso dos recursos (LUO, 2001; GANGOPADHYAY; HUANG; 2004).

Outra etapa importante é a análise dos produtos que serão gerados pelo esforço da cadeia (SOUZA; ROCHA, 2009). Cooper e Slagmulder (1999) explica que os produtos que apresentam baixa margem de lucro e alto nível de funcionalidade são os mais indicados para a aplicação da GCI.

Outros elementos importantes que as empresas precisam considerar na implantação da GCI são: nível de confiabilidade tecnológica e índice de valor (COOPER; SLAGMULDER, 1999). Quanto mais informações tecnológicas a empresa não puder compartilhar com o ambiente externo e quanto menor o índice de valor dos componentes dos produtos, menos indicada é aplicação da GCI.

Cooper e Slagmulder (1999), Kajüter e Kulmala (2005) e Souza e Rocha (2009) apontam algumas características para existir a GCI, como por exemplo, interdependência, estabilidade, cooperação, benefícios mútuos e confiança. A literatura acerca do tema (COOPER; SLAGMULDER, 1999; MOURITSEN et al., 2001; SOUZA; ROCHA, 2009) aponta alguns instrumentos gerenciais que devem ser utilizados para a aplicação da GCI e podem ser divididos em três tipos básicos, sendo eles os mecanismos disciplinadores, capacitores e incentivadores. Esses mecanismos ajudam na gestão de custos ao passo que orientam, controlam, medem, informam e servem de guia para as organizações aplicarem a GCI (SOUZA; ROCHA, 2009).

\subsection{Pesquisas Anteriores}

Dentre as pesquisas bibliométricas sobre GCI, foram identificados dois estudos de autores brasileiros acerca do tema. O primeiro, de Faria et al. (2010), para o período de 1994 a 2009, em nível nacional e internacional, identificou os autores mais referenciados e os periódicos com maior aceitação de artigos das pesquisas em GCI e Contabilidade de Livro Aberto. Foram identificados 30 artigos sobre os dois temas. Cooper e Slagmulder foram os autores mais produtivos (cinco e quatro trabalhos respectivamente), e Management Accounting Research foi o periódico com maior número de trabalhos publicados (sete trabalhos). A pesquisa identificou que havia trabalhos publicados em periódicos de diversas áreas, além de sinalizar uma tendência de crescimento no número de publicações. No Brasil, foram identificados apenas quatro trabalhos publicados acerca da GCI, todos oriundos de pesquisadores vinculados à USP. Dentre os trabalhos, havia somente um artigo aprovado em periódico nacional.

Braga et al. (2012) mapearam a publicação acerca da GCI até o ano de 2010, investigando quais autores haviam sido mais citados nas publicações, quais periódicos mais haviam recebido trabalhos sobre GCI e quais as características e tendências das pesquisas, além de observar os objetivos e abordagens metodológicas apontados pelos autores. Identificaram 48 publicações entre 1992 e 2010, nacionais e internacionais. Constataram que o campo de pesquisa é amplo, recente e praticamente inexplorado. Dos artigos, 27 possuíam objeto empírico, 3 eram casos de pesquisa survey (todos internacionais) e as demais (18) se configuravam como estudos de caso. Constataram que a maioria das pesquisas empíricas sobre GCI são multi-casos e nenhuma de caso único. Concluem que as pesquisas não focaram na criação de um modelo padrão ou um plano de implantação da GCI que pudesse servir de guia para empresas que desejassem utilizar esta prática. Braga et al. (2012) mencionam que os estudos estão bastante focados em diagnosticar a eficácia da GCI ao invés da elaboração de um modelo de implantação, o que consideram natural em função da jovialidade do tema. 


\section{Aspectos Metodológicos}

\subsection{Classificação da Pesquisa}

Este estudo se apresenta na forma de uma pesquisa bibliométrica com análise de conteúdo de parte dos achados, embasada em pesquisa bibliográfica. Caracteriza-se como um estudo exploratório (MARTINS; THEÓPHILO, 2009) ao passo que traz contribuições referentes à classificação e composição metodológica e epistemológica das pesquisas analisadas. A bibliometria surge a partir da necessidade do estudo e da avaliação das atividades de produção e comunicação científica, aplicando métodos para analisar os trabalhos publicados de determinado assunto (ARAÚJO, 2006). A análise de conteúdo, para Jones e Shoemaker (1994), se trata de um método de investigação que formula inferências a partir da identificação sistemática das características contidas nos textos analisados.

Assim, este trabalho tem como escopo as publicações a partir de artigos internacionais publicados em periódicos e, em âmbito nacional, livros, dissertações, teses, monografias, publicações avulsas e outras pesquisas.

\subsection{Coleta de Dados}

A pesquisa deu-se em diversas etapas. Inicialmente foi delimitado o campo de exploração, sendo eventos brasileiros importantes da área contábil e de gestão e bases de dados nacionais e internacionais relevantes na área, conforme Quadro 1.

\begin{tabular}{|l|l|}
\multicolumn{2}{c}{ Quadro 1: Campo de exploração bibliográfica } \\
\hline Eventos Brasileiros & Bases de Dados Bibliográficas \\
\hline . ANPCONT & . Banco de Teses da Capes \\
. Congresso Brasileiro de Custos & . Biblioteca Digital Brasileira de Teses e Dissertações \\
. Congresso USP de Controladoria e Finanças & . EBSCO \\
. EnANPAD & . IEEE XPLORE \\
. SIMPOI & . ISI WEB \\
& . Periódicos Capes \\
& . ProQuest \\
& . SciELO \\
& . Science Direct \\
& . Scopus \\
& . SPELL \\
\hline
\end{tabular}

Fonte: Dados da pesquisa

Nos eventos e nas bases de dados selecionados, foram realizadas buscas com termos em língua portuguesa (interorganizacionais, inter-organizacionais, interorganizacional e interorganizacional) e em língua inglesa (interorganizational cost management, interorganizational cost management, interorganisational cost management e inter-organisational cost management). As buscas foram realizadas sem delimitação de datas inicial e final, sempre com a opção "todos os campos do texto", e os termos colocados entre aspas.

$\mathrm{Na}$ sequência foram lidos os títulos dos trabalhos e, quando julgado necessário, feita a leitura dos resumos para exclusão daqueles que mencionavam o termo, mas não tratavam especificamente do assunto. Assim, foram selecionados os estudos que comporiam, até então, a amostra desta pesquisa, no total de 46 trabalhos (18 nacionais e 28 internacionais). Além destes, foi realizada nova busca que partiu da análise das referências dos trabalhos nacionais encontrados, com o intuito de preencher alguma lacuna que poderia existir após as etapas anteriores. Com isso foram selecionados outros 5 trabalhos internacionais e 4 nacionais, totalizando 55 trabalhos, sendo 22 brasileiros (40\% da amostra) e 33 internacionais (60\% da amostra). O Quadro 2 demonstra a participação de cada tipo de publicação, na amostra desta pesquisa. 
Quadro 2: Tipos de trabalhos identificados

\begin{tabular}{|l|c|c|}
\hline Tipos de Trabalho & Quantidade & Participação \\
\hline Periódicos Internacionais & 31 & $56,3 \%$ \\
\hline Eventos Nacionais & 12 & $21,8 \%$ \\
\hline Dissertações de Mestrado Nacionais & 5 & $9,0 \%$ \\
\hline Periódicos Nacionais & 3 & $5,4 \%$ \\
\hline Livros Internacionais & 2 & $3,6 \%$ \\
\hline Livro Nacional & 1 & $1,8 \%$ \\
\hline Tese de Doutorado & 1 & $1,8 \%$ \\
\hline Total & $\mathbf{5 5}$ & $\mathbf{1 0 0 \%}$ \\
\hline
\end{tabular}

Fonte: Dados da pesquisa

$\mathrm{Na}$ pesquisa realizada também retornaram artigos publicados em eventos internacionais (oito artigos), que não foram incluídos no trabalho, assim como capítulos de livros que discutiam o assunto (dois capítulos de livros internacionais), uma vez que o foco da análise internacional está nos artigos publicados em periódicos. $\mathrm{Na}$ análise nacional foram incluídos trabalhos além dos encontrados em periódicos, motivado pela baixa quantidade de artigos nacionais em periódicos.

A coleta de dados ocorreu no período de abril a junho de 2014 e as publicações identificadas são do período de 1992 a 2013.

\subsection{Procedimentos após a Coleta dos Dados}

Os artigos foram transferidos para um banco de dados, em seguida, foi realizada a leitura e tabulada as informações referentes a cada artigo. Foram analisados o tipo de trabalho, os autores, o ano da publicação e o evento ou periódico em que os trabalhos foram publicados.

Num segundo momento, os artigos publicados em periódicos foram analisados epistemologicamente, sendo descritos a plataforma teórica, as estratégias metodológicas, as teorias e os paradigmas de pesquisa.

Quanto às estratégias metodológicas, foram classificadas em pesquisa de campo, survey, modelos e análise bibliométrica.

Pesquisa de campo: Segundo Gonsalves (2003), a pesquisa de campo busca as informações diretamente com a população pesquisada, exigindo do pesquisador um encontro mais próximo com os pesquisados. Nesse caso, o pesquisador precisa ir ao espaço onde o fenômeno ocorre ou ocorreu e reunir um conjunto de informações a serem documentadas.

Levantamento ou Survey: Segundo Gil (1999, p. 70), as pesquisas de levantamento "se caracterizam pela interrogação direta das pessoas cujo comportamento se deseja conhecer. Basicamente, procede-se a solicitação de informações a algum grupo significativo de pessoas acerca do problema estudado, para em seguida, mediante análise quantitativa, obter as conclusões correspondentes aos dados coletados".

Modelos: Hesford et al. (2007) explicam que é uma pesquisa metodologicamente rigorosa, que visa construir uma representação em escala menor da realidade, podendo ser resultado de extenso trabalho empírico de campo ou da análise de conceitos. Os modelos buscam explicar a realidade por meio de análises dedutivas.

Análise bibliográfica: Carvalho (1988, p. 110) define como "a atividade de localização e consulta de fontes diversas de informação escrita, para coletar dados gerais ou específicos a respeito de determinado tema". O pesquisador deve consultar fontes secundárias, como por exemplo, livros, periódicos, anais de eventos científicos e documentos escritos, para obter as informações necessárias para desenvolver o estudo. 
Para classificar os tipos de paradigmas de pesquisa, foi utilizada a classificação proposta por Burrell e Morgan (1979). Os autores explicam que as teorias das ciências sociais podem ser classificadas em quatro paradigmas principais, sendo eles:

Humanismo Radical: Os autores explicam que a principal ênfase deste paradigma está na consciência do ser humano, sendo interesse deste paradigma excluir o ser humano das restrições que a sociedade impõe ao desenvolvimento das pessoas. Ou seja, enquadram-se neste paradigma as pesquisas que são simpatizantes da mudança social.

Interpretativo: $\mathrm{O}$ foco deste paradigma está em entender como o mundo é. $\mathrm{O}$ interesse maior das pesquisas que se classificam neste paradigma é entender a natureza fundamental do mundo social, ou seja, têm interesse no entendimento da essência do mundo e do seu dia a dia.

Estruturalismo Radical: O foco deste paradigma está na mudança radical sob um ponto de vista objetivo. Este paradigma é caracterizado pelo estudo de conflitos fundamentais que ocorrem na sociedade contemporânea, convergindo em mudanças radicais. Esses conflitos podem ocorrer, por exemplo, diante de crises políticas ou crises econômicas, e são estes conflitos que geram mudanças nas estruturas sociais.

Funcionalismo: Este paradigma ocupa-se com o estudo das organizações. As pesquisas pautadas neste paradigma possuem um ponto de vista objetivo e buscam gerar conhecimentos que visam soluções práticas para os problemas.

\section{Descrição e Análise dos Resultados}

\subsection{Visão Geral das Publicações em GCI}

A distribuição das publicações identificadas é mostrada na Figura 1, onde se observa que a primeira publicação ocorreu em 1992.

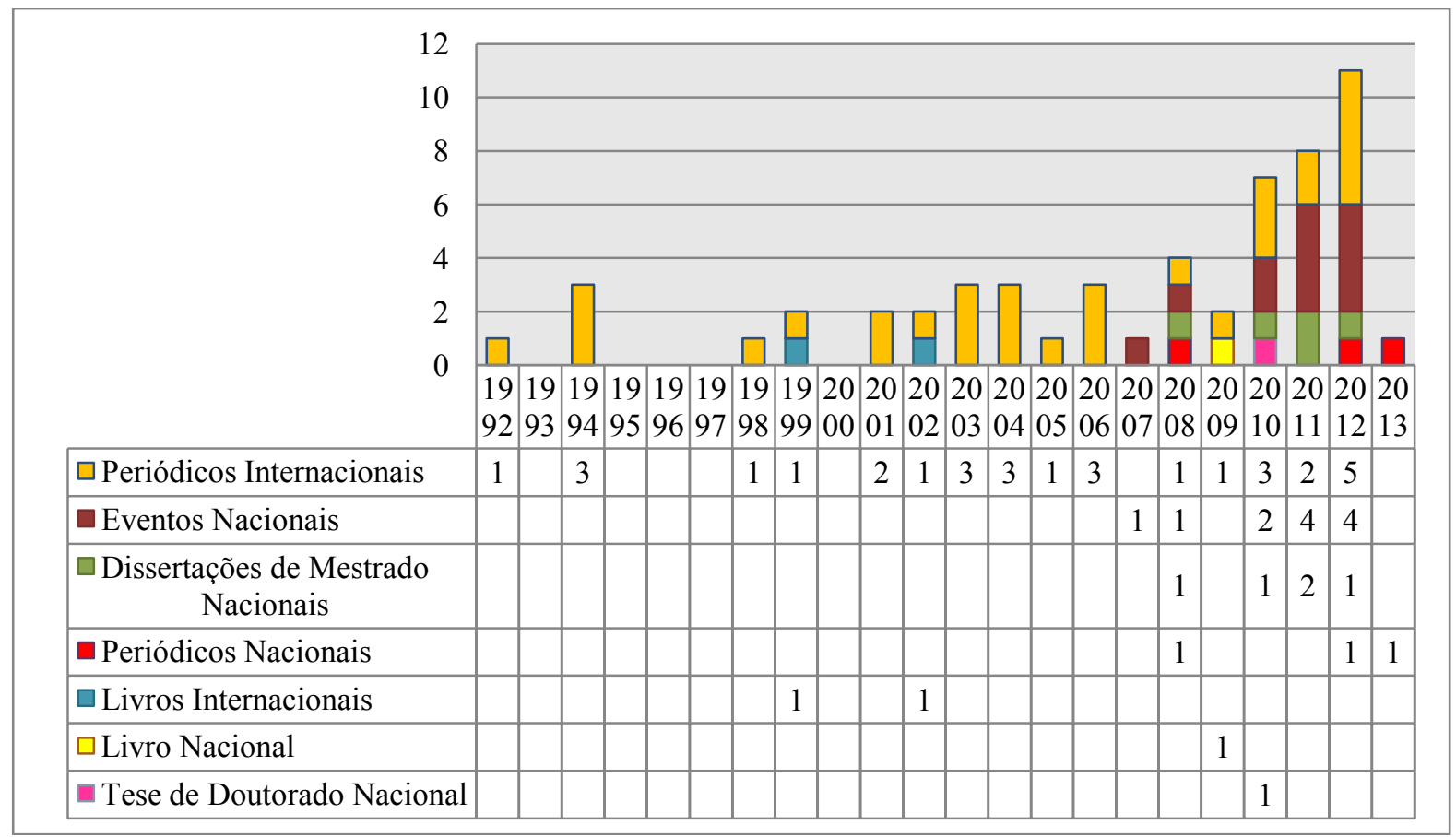

Figura 1 - Número de trabalhos publicados sobre GCI

Fonte: Dados da pesquisa

O primeiro trabalho publicado, a partir da seleção realizada, foi um artigo de Munday (1992) publicado no Management Accounting Research que, entre outros objetivos, buscou 
examinar os custos compartilhados entre os compradores e fornecedores. $\mathrm{O}$ autor usou o termo shared costs para conduzir seu estudo, como também observaram Braga et al. (2012).

O termo Interorganizational Cost Management apareceu apenas mais tarde, em 1994, em três trabalhos publicados por Robin Cooper. Esses trabalhos foram resultado do Japan Project, que iniciou em 1989 (COOPER, 1994), no qual Cooper fez estudos acerca das práticas japonesas da gestão de custos, constatando que as empresas japonesas vinham desenvolvendo sistemas de Gestão de Custos Interorganizacionais. Os trabalhos de 1994 estão entre os pioneiros acerca do tema, demonstrando, inclusive, estudos de caso e aplicações da GCI na prática.

A partir da Figura 1 nota-se que o período entre 1995 e 1997 é um intervalo em que não houve publicações acerca do assunto. Nesse período o professor Robin Cooper, que até então somava três trabalhos sobre o tema, não teve publicações, voltando a produzir, nos anos seguintes, um artigo (COOPER; SLAGMULDER, 1998) e um livro (COOPER; SLAGMULDER, 1999). Este é o único livro identificado que traz em seu título o termo Interorganizational Cost Management.

A partir de 2001, com exceção de 2007, foram identificados trabalhos publicados em periódicos internacionais em todos os anos, existindo relativa constância entre o período de 2001 a 2006, com uma média de duas publicações por ano. Considerando todos os tipos de trabalhos encontrados, apenas em cinco anos, dentre os 22 que a pesquisa abrange, não foram identificadas publicações sobre o tema.

Em 2013 ocorreu apenas uma publicação, e em periódico nacional, fato que foge à tendência de crescimento que vinha acontecendo nos últimos anos e contrasta com o ano anterior, que foi o ápice das publicações sobre o tema. Acredita-se que o baixo número de pesquisas em 2013 é devido à "demora" por parte das bases de dados em atualizar seus acervos.

Essa primeira etapa da descrição e análise dos resultados buscou mostrar, brevemente, a origem e comportamento das publicações acerca da GCI até o momento. A análise mais detalhada dos dados ocorre na sequência, separada por cenário: brasileiro e internacional.

\subsection{Publicações em GCI no Brasil}

A distribuição, por tipo, das publicações brasileiras sobre GCI, está elencada no Quadro 3 e na Figura 2. Observa-se que os eventos destacam-se como o principal responsável pelas publicações dos trabalhos brasileiros, representando 54,5\% do total. A descrição dos eventos ocorrerá posteriormente, por meio do Quadro 4 e da Figura 3.

Quadro 3: Publicações brasileiras sobre GCI, por tipo

\begin{tabular}{|l|c|c|}
\hline Tipos de Trabalho & Quantidade & Participação \\
\hline Evento & 12 & $54,5 \%$ \\
\hline Dissertação de Mestrado & 5 & $22,7 \%$ \\
\hline Periódico & 3 & $13,6 \%$ \\
\hline Livro & 1 & $4,5 \%$ \\
\hline Tese de Doutorado & 1 & $4,5 \%$ \\
\hline Total & $\mathbf{2 2}$ & $\mathbf{1 0 0 \%}$ \\
\hline
\end{tabular}

Fonte: Dados da pesquisa 


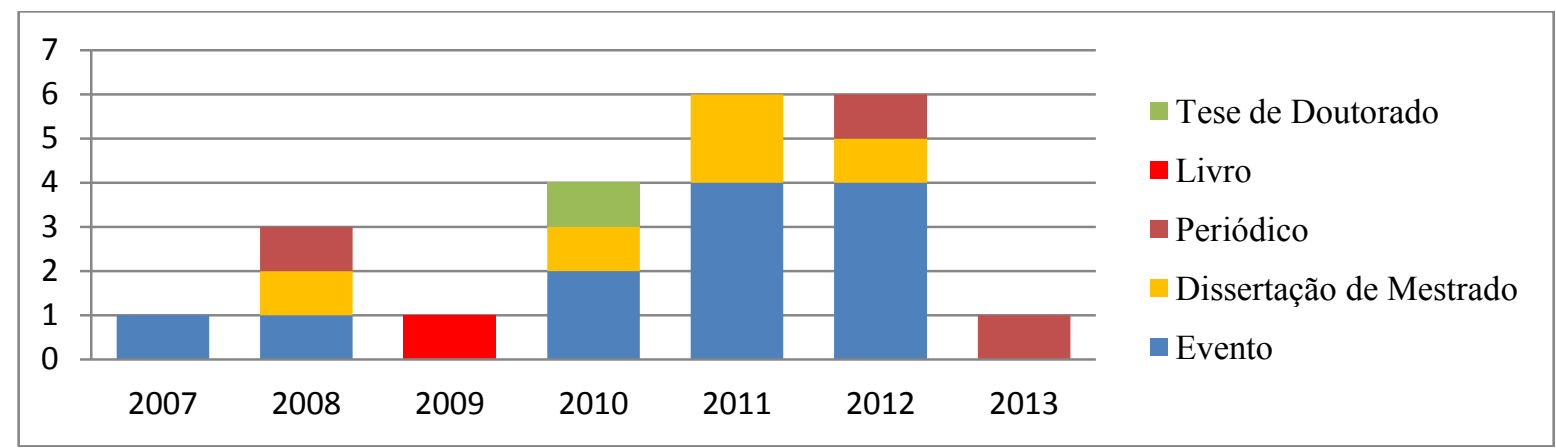

Figura 2 - Publicações brasileiras sobre GCI, por ano

Fonte: Dados da pesquisa

Foram identificadas cinco dissertações de mestrado em universidades brasileiras, sendo que cada uma foi apresentada a uma instituição diferente, sendo elas a FEA/USP, FUCAPE, USCS, UFPR e UNISINOS, não havendo assim um polo de pesquisa que concentre os trabalhos em alguma instituição.

Há um baixo número de publicações em periódicos nacionais - apenas três. Essas publicações foram realizadas por três periódicos diferentes, sendo eles a BASE - Revista de Administração e Contabilidade da UNISINOS, a ABCustos e a Revista Brasileira de Gestão de Negócios. O fato de o assunto ser novo talvez seja uma razão para o baixo número de publicações nos periódicos brasileiros sobre o tema, que ainda se observa.

Apenas um livro escrito por autores brasileiros aborda especificamente o tema, sendo a obra de Souza e Rocha (2009), que explica como funciona e qual é a utilidade da GCI nas organizações, e oferece um modelo prático para que se possa avaliar a maior ou menor aplicabilidade desse método a cada empresa. A tese de doutorado identificada foi publicada por Camacho (2010), e apresentada à FEA/USP.

O Quadro 4 e a Figura 3 expõem como os artigos foram distribuídos entre os eventos brasileiros. O Congresso Brasileiro de Custos e o Congresso USP de Controladoria e Finanças juntos somam mais de $65 \%$ das publicações.

Quadro 4: Publicações de artigos que versam sobre GCI nos eventos brasileiros

\begin{tabular}{|l|c|c|}
\hline Eventos Nacionais & Quantidade & Participação \\
\hline Congresso Brasileiro de Custos & 5 & $41,7 \%$ \\
\hline Congresso USP de Controladoria e Finanças & 3 & $25,0 \%$ \\
\hline EnANPAD & 2 & $16,7 \%$ \\
\hline SIMPOI & 1 & $8,3 \%$ \\
\hline ANPCONT & 1 & $8,3 \%$ \\
\hline Total & $\mathbf{1 2}$ & $\mathbf{1 0 0 \%}$ \\
\hline
\end{tabular}

Fonte: Dados da pesquisa

O congresso USP de Controladoria e Finanças foi pioneiro em publicar artigos a respeito da GCI, sendo do ano de 2007 a primeira publicação, de Aguiar e Rocha (2007), com o objetivo de desenvolver uma análise do relacionamento entre a estrutura conceitual da abordagem da GCI proposta por Cooper e Slagmulder e o Open Book Accounting. 


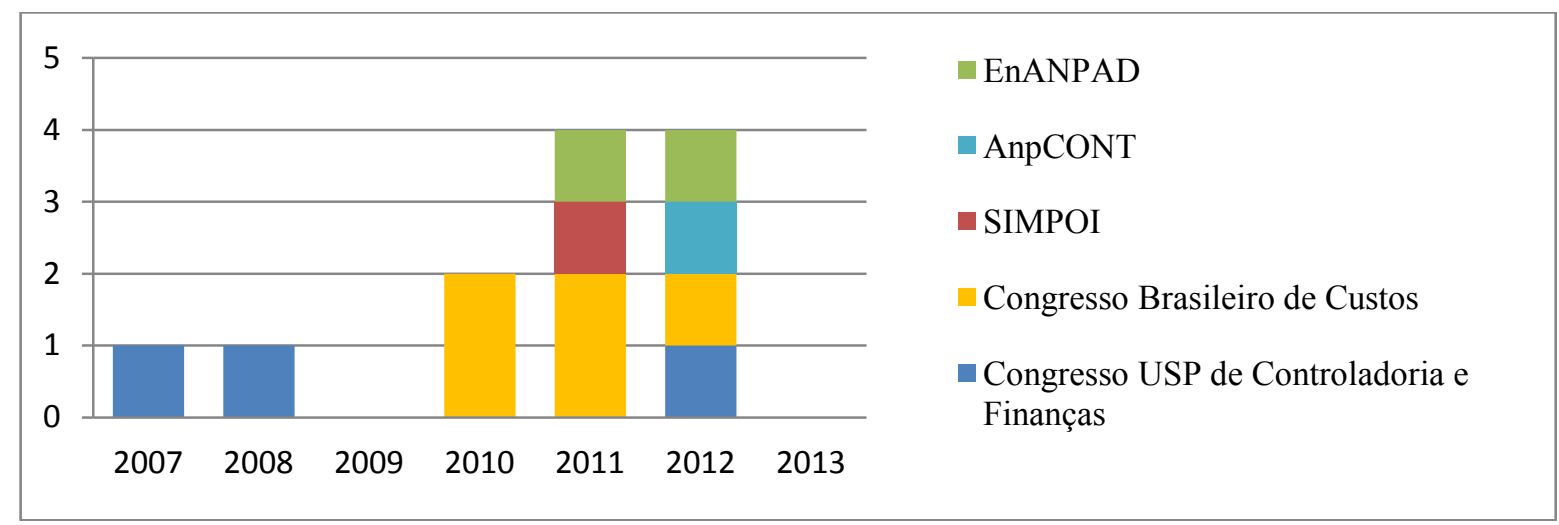

Figura 3 - Publicações de artigos que versam sobre GCI nos eventos brasileiros, por ano

Fonte: Dados da pesquisa

Referindo-se aos autores, e considerando todos os tipos de publicação (artigos em periódicos, artigos em eventos, livros, teses e dissertações), foi possível especificar quais foram os autores que publicaram sobre o tema, e a frequência com que essas publicações ocorreram. Por meio do levantamento se observou que 28 autores brasileiros tiveram algum tipo de publicação, sendo que 14 publicaram uma única vez. A Figura 4 elenca aqueles que tiveram pelo menos 2 publicações (14 autores).

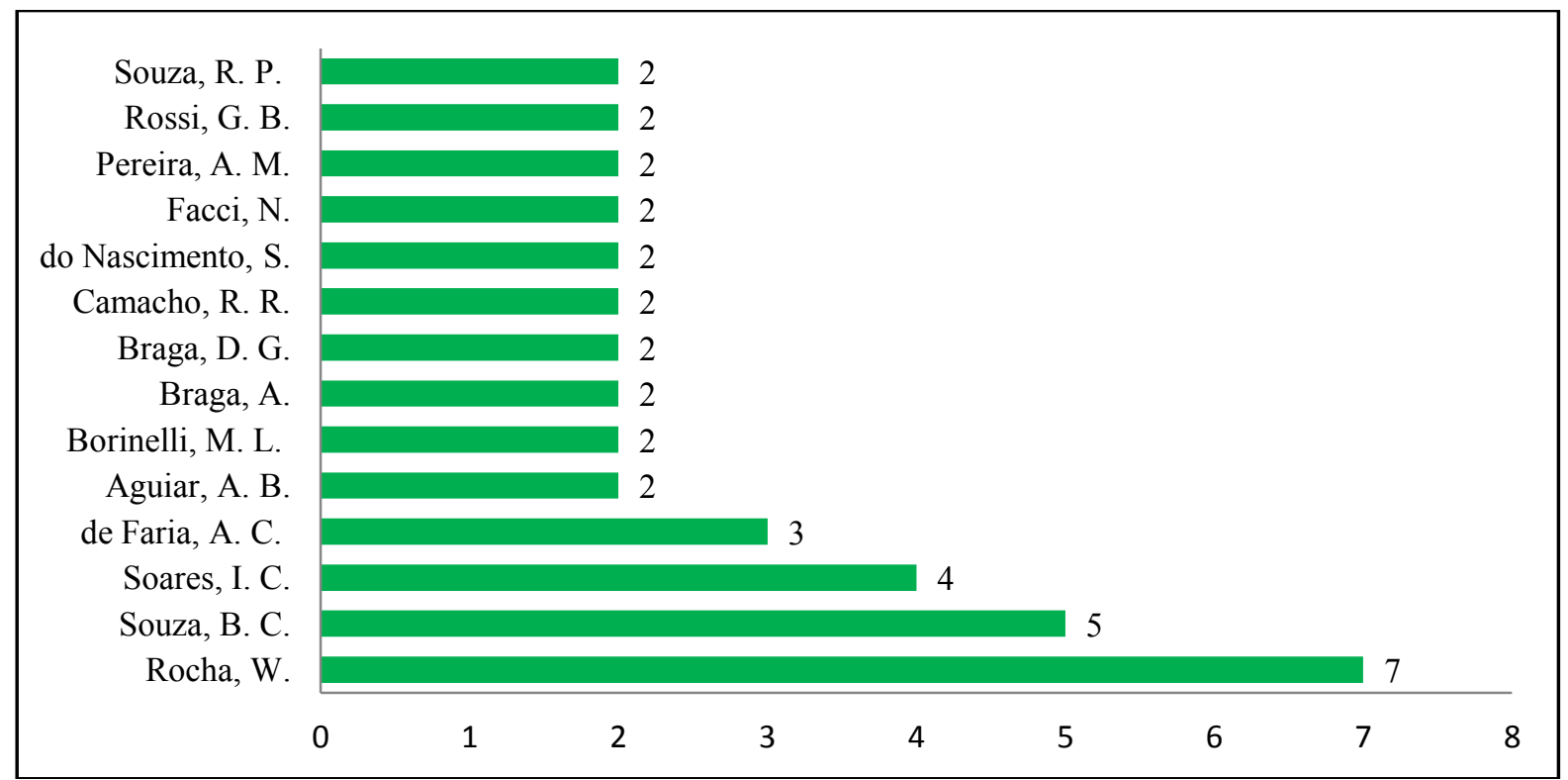

Figura 4 - Número de trabalhos de GCI publicados por autores brasileiros com duas ou mais publicações Fonte: Dados da pesquisa

Todas as publicações de autores brasileiros foram feitas a partir de 2007, demonstrando que são recentes, sendo a última em 2013 (FARIA et al., 2013). Os autores mais produtivos, no Brasil, e considerando os parâmetros definidos nesta pesquisa, são Welington Rocha e Bruno Carlos de Souza, com sete e cinco trabalhos respectivamente. Esses dois autores participaram da elaboração, juntos ou não, de 10 trabalhos, o que representa cerca de $43 \%$ dos trabalhos brasileiros. Entre seus trabalhos estão um livro, seis artigos em eventos, dois em periódicos nacionais e uma dissertação de mestrado.

A análise dos autores brasileiros possibilitou a formação de um sociograma, mostrado na Figura 5 e que ajuda a compreender de que maneira os autores se organizaram para publicar acerca do tema, demonstrando todos os autores nacionais (28). 


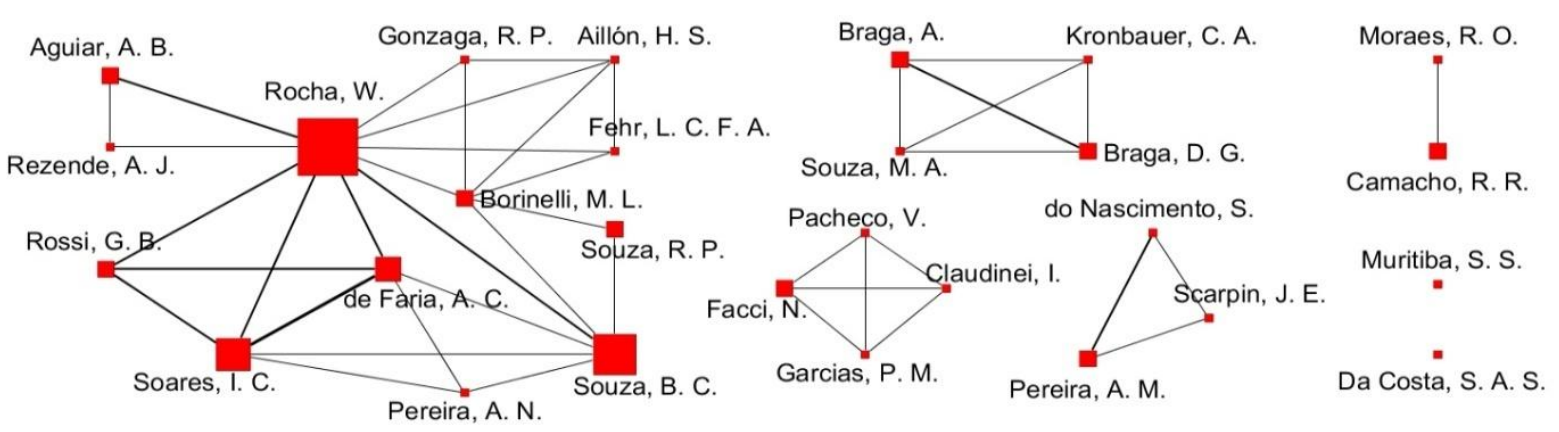

Figura 5 - Sociograma com os autores brasileiros que publicaram acerca de GCI

Fonte: Dados da pesquisa

Cada ponto vermelho da figura representa um autor. O tamanho de cada quadrado e a proporção entre eles são justificados pelo número de publicações realizadas. Outro fator a ser destacado está nas linhas que interligam os autores que, quanto mais espessas, maior o número de trabalhos realizados em conjunto. Ao todo, foram identificados apenas 7 arranjos, ou seja, os 28 autores identificados formaram 3 redes (aqui denominados de redes aqueles grupos formados por mais de três autores), 1 trio, 1 dupla e 2 autores escreveram individualmente.

\subsection{Publicações Internacionais sobre GCI}

Como apontado anteriormente, o levantamento dos trabalhos internacionais é representado por artigos publicados em periódicos (31) e livros (2). O Quadro 5 e a Figura 6 mostram os periódicos internacionais que publicaram artigos sobre GCI.

Quadro 5: Publicações de artigos que versam sobre GCI em periódicos internacionais

\begin{tabular}{|l|c|c|}
\hline Nome do Periódico & Quantidade & Participação \\
\hline Management Accounting Research & 7 & $22,6 \%$ \\
\hline International Journal of Production Economics & 3 & $9,7 \%$ \\
\hline Accounting, Organizations and Society & 3 & $9,7 \%$ \\
\hline Financial Management & 3 & $9,7 \%$ \\
\hline Journal of Cost Management & 2 & $6,4 \%$ \\
\hline Journal of Purchasing and Supply Management & 2 & $6,4 \%$ \\
\hline Outros (1 artigo em cada periódico) & 11 & $35,5 \%$ \\
\hline Total & $\mathbf{3 1}$ & $\mathbf{1 0 0 \%}$ \\
\hline
\end{tabular}

Fonte: Dados da pesquisa

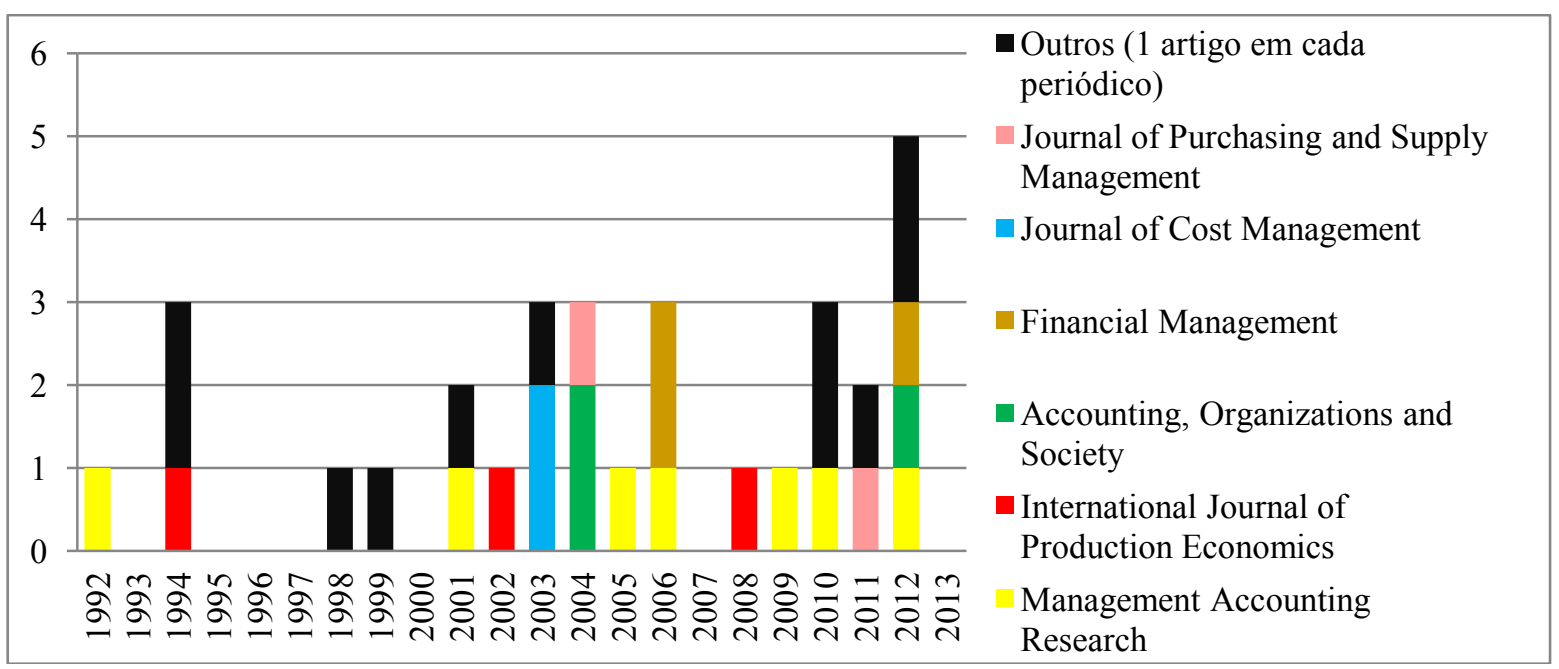

Figura 6 - Publicações de artigos que versam sobre GCI em periódicos internacionais, por ano 
Fonte: Dados da pesquisa

O Management Accounting Research é o periódico internacional que mais publicou trabalhos sobre GCI e, juntamente com os três seguintes, concentraram cerca de $53 \%$ do total de artigos publicados nesses periódicos internacionais. Observa-se, assim, concentração das publicações em poucos periódicos. Baxter e Chua (2003) explicam que periódicos como Management Accounting Research e o Accounting Organizations and Society têm ajudado a aumentar o número de trabalhos qualitativos de campo na área de contabilidade gerencial. Cabe frisar que dos dezessete periódicos que publicaram trabalhos sobre GCI, onze publicaram apenas um artigo.

Outro ponto a ser destacado é a heterogeneidade dos periódicos. Foram identificados trabalhos em periódicos que trazem em seu nome termos como: accounting, financial management, industrial marketing, supply management, logistics management, production economics e cost management, o que é um indício de que a gestão integrada entre empresas é de interesse de vários ramos do conhecimento e não apenas da área de custos.

A Figura 7 mostra o número de produções dos autores internacionais. Ao todo, foram identificados 45 autores internacionais nos trabalhos da amostra (artigos e livros), sendo que apenas 10 tiveram duas ou mais produções publicadas.

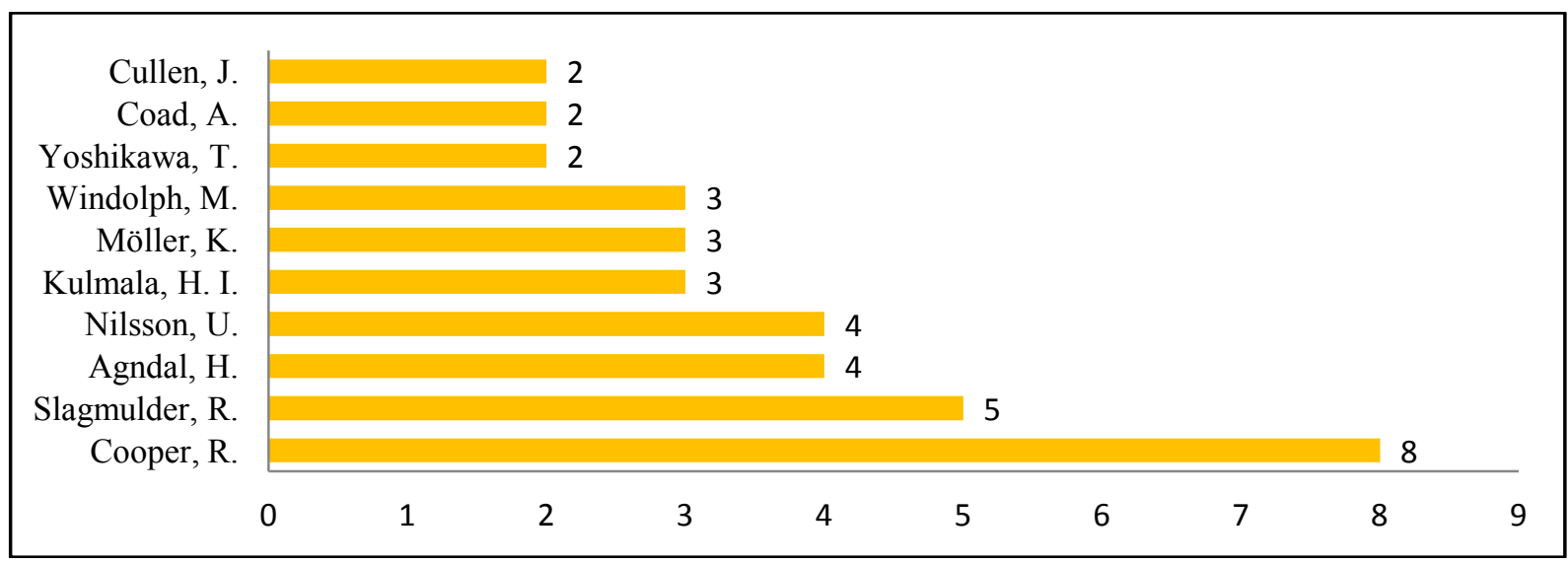

Figura 7 - Número de trabalhos de GCI publicados por autores internacionais com duas ou mais publicações

Fonte: Dados da pesquisa

Os autores mais produtivos são Robin Cooper, que participou de oito trabalhos, e Regine Slagmulder, que participou de cinco trabalhos, sendo todos em conjunto com Cooper. Eles são autores do livro Supply Chain Development for the Lean Enterprise: Interorganizational Cost Management - obra recorrente nas referências dos trabalhos sobre Gestão de Custos Interorganizacionais. Entretanto, há cerca de uma década não publicam nenhuma obra sobre o tema, sendo a última produção um artigo de 2004 (COOPER; SLAGMULDER, 2004).

O outro livro internacional identificado é Cost Management in Supply Chains, de Seuring e Goldbach (2002), no qual os editores da obra coordenaram o trabalho de 35 autores, que fornecem insights sobre novos conceitos para controle de custos nas cadeias de suprimento. O livro contém 23 capítulos que abordam temas da gestão de cadeias de suprimento e gestão de custos - entre eles a Gestão de Custos Interorganizacionais -, relatando sua importância para que as empresas consigam responder à crescente concorrência global e exigências dos clientes.

A Figura 8 demonstra, por meio de um sociograma, como se deram os arranjos entre os autores que produziram trabalhos sobre GCI. Os 33 trabalhos internacionais do levantamento foram produzidos por 45 autores diferentes. 


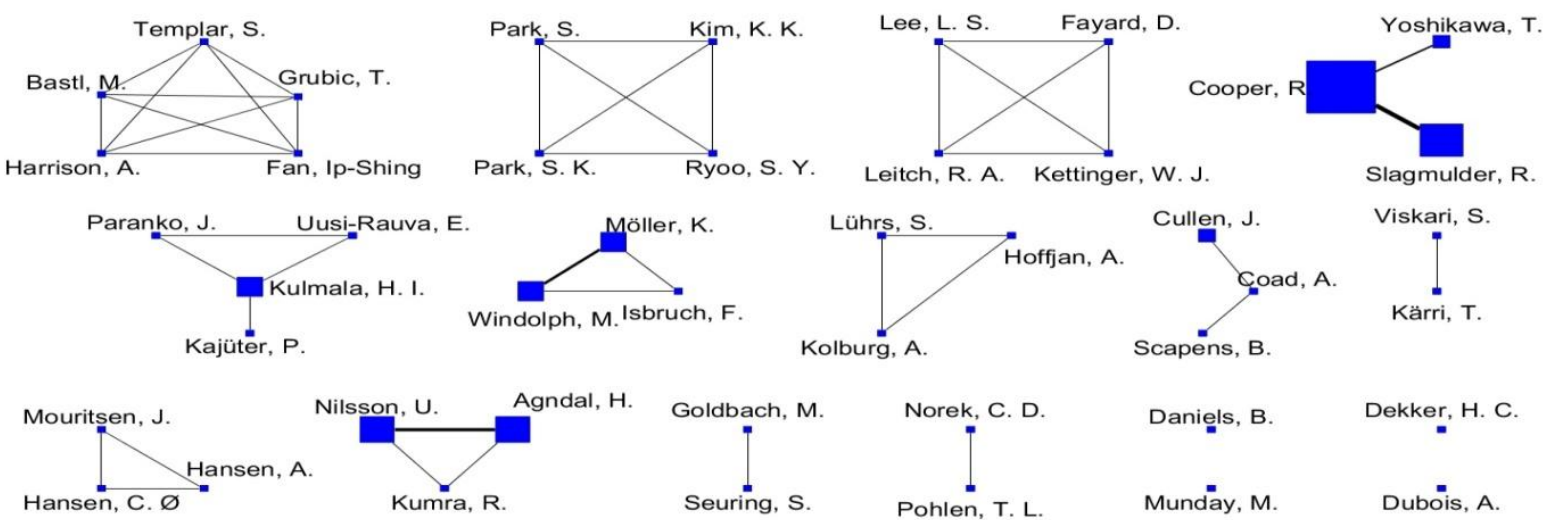

Figura 8 - Sociograma com os autores internacionais que publicaram acerca da GCI Fonte: Dados da pesquisa

Cada ponto azul da figura representa um autor. Assim como na representação realizada para os autores brasileiros, neste sociograma o tamanho de cada quadrado e a proporção entre eles são justificados pelo número de publicações e, quanto mais espessas as linhas que interligam os autores, maior o número de trabalhos realizados entre eles.

No cenário internacional, os autores formaram 17 arranjos, ou seja, os 45 autores identificados formaram 4 redes (aqui denominados de redes aqueles grupos formados por mais de três autores), 6 trios, 3 duplas e 4 autores escreveram individualmente.

\subsection{Análise de Conteúdo dos Artigos Publicados em Periódicos}

\subsubsection{Plataforma Teórica}

Os 34 artigos publicados em periódicos citaram 1.411 fontes. Os dados apresentaram alta dispersão, já que o artigo com o maior número de citações utilizou 127 fontes, enquanto outros utilizaram menos de 10 fontes. $\mathrm{Na}$ análise da plataforma teórica dos trabalhos encontrados, foi levantada a média de fontes utilizadas pelos autores e a idade média delas, representado pelo Quadro 6. Posteriormente, foram analisados os tipos de fonte utilizada, representada pelo Quadro 7.

Quadro 6: Média de citação por artigo e idade média das fontes, em anos, dos artigos acerca da GCI publicados em periódicos

\begin{tabular}{|c|c|c|}
\hline & \multicolumn{2}{|l|}{ publicados em periódicos } \\
\hline & Média de citações por artigo & Idade média das fontes (em anos) \\
\hline $\begin{array}{l}31 \text { Artigos publicados em periódicos } \\
\text { internacionais }\end{array}$ & 45,8 & 8,5 \\
\hline $\begin{array}{l}3 \text { Artigos publicados em periódicos } \\
\text { nacionais }\end{array}$ & 27,7 & 7,9 \\
\hline 34 Artigos publicados em periódicos & 44,2 & 8,4 \\
\hline
\end{tabular}

Fonte: Dados da pesquisa

Quadro 7: Tipos de fontes utilizadas pelos artigos acerca da GCI publicados em periódicos

\begin{tabular}{|l|c|c|c|c|c|c|c|}
\cline { 2 - 7 } & \multicolumn{6}{c|}{ Tipos de fontes utilizadas pelos artigos } \\
\cline { 2 - 8 } & $\begin{array}{c}\text { Artigos em } \\
\text { periódicos }\end{array}$ & Livros & $\begin{array}{c}\text { Artigos em } \\
\text { eventos }\end{array}$ & Dissertações & Teses & Outros & Total \\
\hline $\begin{array}{l}\text { 31 Artigos publicados em periódicos } \\
\text { internacionais }\end{array}$ & $77,0 \%$ & $19,4 \%$ & $1,3 \%$ & $0,6 \%$ & $0,6 \%$ & $1,1 \%$ & $100 \%$ \\
\hline $\begin{array}{l}3 \\
\text { A Artigos publicados em periódicos } \\
\text { nacionais }\end{array}$ & $51,8 \%$ & $26,5 \%$ & $12,0 \%$ & $4,8 \%$ & $2,4 \%$ & $2,4 \%$ & $100 \%$ \\
\hline 34 Artigos publicados em periódicos & $74,7 \%$ & $20,0 \%$ & $2,3 \%$ & $1,0 \%$ & $0,8 \%$ & $1,2 \%$ & $100 \%$ \\
\hline
\end{tabular}

Fonte: Dados da pesquisa

Gestão de Custos Interorganizacionais: um Estudo Bibliométrico 
Existe uma predominância na citação de artigos publicados em periódicos, superando, inclusive, os livros. Fato importante, já que, segundo Martins e Bernadelli (2005), são os artigos que expressam a dinâmica e as fronteiras em qualquer área de conhecimento.

Quanto ao número de referências utilizadas pelos artigos, onze artigos citaram dez ou menos trabalhos, o que pode ser considerado pouco para a construção de um referencial teórico de um trabalho científico. Percebe-se que os artigos internacionais possuem mais articulação de conteúdo do que aos artigos nacionais.

Muitos trabalhos utilizaram livros como principal fonte de referência para a elaboração da pesquisa. Também se observou baixa utilização de teses e dissertações. Acredita-se que este número tende a aumentar, devido ao crescimento de programas pósgraduação em ciências contábeis no Brasil. Essa situação corrobora com os achados de Nascimento, Junqueira e Martins (2010), ao analisarem artigos publicados em eventos nacionais relacionados à contabilidade.

\subsubsection{Estratégias Metodológicas}

Yin (2001) explica que as pesquisas de campo são descritivas, avaliativas e visam gerar teorias. Segundo o autor, as pesquisas de campo são mais utilizadas quando os pesquisadores conduzem seus estudos pautados em questões centradas em "como?" e "por que?".

Foram classificadas como pesquisas survey aquelas que apresentaram caráter descritivo, ou seja, pesquisas que apenas descreveram as características das organizações observadas, não apresentando inferências ou gerando teorias. Essas pesquisas se caracterizam principalmente pela atuação do pesquisador-observador, e descrevem a realidade das organizações por meio de levantamentos ou pesquisas de opinião.

Os modelos criados pelos artigos acerca da GCI são resultados de pesquisas de campo, após observação da realidade, nunca de cenários fictícios. As propostas de modelo identificadas apresentam os mesmos problemas apontados por Theóphilo e Iudícibus (2005), que afirmam que a maioria dos modelos é formulada após a observação de poucas situações reais, ou seja, autores observam poucos casos e generalizam, apresentando os achados na forma de modelos.

As pesquisas classificadas como análises bibliográficas foram aquelas que consultaram fontes de informações escritas para coletar dados gerais ou específicos a respeito da GCI. As fontes utilizadas são secundárias, como livros, periódicos, anais de eventos científicos e documentos escritos, para obter as informações necessárias para desenvolver o estudo (CARVALHO, 1988).

O Quadro 8 demonstra as estratégias metodológicas dos artigos publicados em periódicos.

Quadro 8: Estratégias metodológicas utilizadas pelos artigos acerca da GCI publicados em periódicos

\begin{tabular}{|l|c|c|c|c|c|}
\cline { 2 - 6 } \multicolumn{1}{c|}{} & \multicolumn{5}{c|}{ Estratégias Metodológicas } \\
\cline { 2 - 6 } & $\begin{array}{c}\text { Pesquisa de } \\
\text { campo }\end{array}$ & Survey & Modelos & $\begin{array}{c}\text { Análise } \\
\text { bibliográfica }\end{array}$ & Total \\
\hline $\begin{array}{l}31 \text { Artigos publicados em periódicos } \\
\text { internacionais }\end{array}$ & $48,4 \%$ & $19,4 \%$ & $19,4 \%$ & $9,7 \%$ & $100 \%$ \\
\hline $\begin{array}{l}3 \text { Artigos publicados em periódicos } \\
\text { nacionais }\end{array}$ & $66,7 \%$ & $0,0 \%$ & $0,0 \%$ & $33,3 \%$ & $100 \%$ \\
\hline 34 Artigos publicados em periódicos & $50,0 \%$ & $17,6 \%$ & $17,6 \%$ & $11,8 \%$ & $100 \%$ \\
\hline
\end{tabular}

Fonte: Dados da pesquisa 
Os achados acerca do tipo de estratégias metodológicas usadas nas pesquisas acerca da GCI corroboram com os achados de Nascimento, Junqueira e Martins (2010) e Hesford et al. (2007), que conduziram estudos bibliométricos no campo da contabilidade gerencial, ao passo que as pesquisas de campo se apresentam com a principal estratégia metodológica utilizada para a condução das pesquisas.

Os estudos de campo são os mais expressivos. Foram utilizados principalmente como estudos de caso, onde os pesquisadores buscaram compreender a realidade das empresas, com o intuito criar conhecimento. $\mathrm{O}$ setor automotivo foi bastante utilizado como cenário das pesquisas de campo, destacando-se as pesquisas pioneiras realizadas no Japão.

Nas pesquisas de campo observadas, foram identificados problemas citados por Theóphilo e Iudícibus (2005), que observaram que muitos trabalhos configuram-se apenas como meras demonstrações das práticas das empresas, sem apresentar o rigor e profundidade que este tipo de pesquisa exige, ou seja, sem apresentar protocolos, validação e imersão nos dados.

Cerca de $12 \%$ dos trabalhos fizerem uso de livros, artigos e outros documentos escritos para coletar os dados e formular seus estudos. Esses autores buscaram apurar o que estava escrito sobre temas específicos que se relacionam com a GCI.

Observa-se que não foram encontrados trabalhos que executaram experimentos. A pesquisa experimental pode ser considerada o ideal da ciência porque as respostas às questões de pesquisa obtidas em experimentos são, geralmente, mais claras e menos ambíguas do que as respostas obtidas em pesquisas não-experimentais (KERLINGER, 1991).

Do mesmo modo, não foram encontradas pesquisas documentais, ou seja, aquelas que utilizam fontes disponíveis publicamente pelas organizações, tais como demonstrações contábeis e informações exigidas por órgãos governamentais.

\subsubsection{Origem das Teorias Utilizadas}

Segundo Hesford et al. (2007), as principais teorias utilizadas nas pesquisas, no campo da contabilidade gerencial, são advindas da economia, psicologia e sociologia. O autor cita ainda que algumas pesquisas utilizam a combinação de mais de uma teoria.

Com o intuito de demonstrar as teorias utilizadas pelas pesquisas, foi adicionada a coluna "conceitos" no Quadro 9, para enquadrar aquelas pesquisas que não utilizam teorias como plano de fundo, utilizando apenas conceitos criados por outros autores. É importante que haja a diferenciação entre conceito e teoria, já que a utilização de conceitos isolados não cria uma teoria (NASCIMENTO; JUNQUEIRA; MARTINS, 2010).

O Quadro 9 demonstra as teorias utilizadas pelos artigos.

\begin{tabular}{|c|c|c|}
\hline & \multicolumn{2}{|c|}{ Teorias Utilizadas } \\
\hline & Conceitos & Ciências Sociais \\
\hline $\begin{array}{l}31 \text { Artigos publicados em periódicos } \\
\text { internacionais }\end{array}$ & $96,8 \%$ & $3,2 \%$ \\
\hline $\begin{array}{l}3 \text { Artigos publicados em periódicos } \\
\text { nacionais }\end{array}$ & $100 \%$ & $0,0 \%$ \\
\hline 34 Artigos publicados em periódicos & $97,1 \%$ & $2,9 \%$ \\
\hline
\end{tabular}

Fonte: Dados da pesquisa

A maioria dos trabalhos não aborda uma teoria que explica a realidade, fato que corrobora com os achados de Theóphilo e Iudícibus (2005) e Nascimento, Junqueira e Martins (2010). A maior parte dos trabalhos analisados utilizou conceitos como plano de fundo para desenvolver as pesquisas, citando achados e modelos postulados pela literatura acerca da GCI. 
Sutton e Staw (1995) explicam que a utilização desses conceitos é relevante para a compreensão dos termos do trabalho, mas não configura uma teoria.

Kajüter e Kulmala (2005) foi o único artigo identificado que utilizou uma teoria como plano de fundo - a Teoria da Contingência. Burns e Stalker (1961) e Chandler (1962) deram início a essa teoria ao pesquisar o impacto do ambiente e da estratégia na estrutura organizacional. Após estes trabalhos, um grande número de pesquisas na área da contabilidade foi produzido com a abordagem contingencial (CAMACHO, 2010).

Segundo Cooper e Hopper (2006) e Miller (2007), os trabalhos de Geertz, Giddens, Foucault, Habermas e Marx, são comumente utilizados como base teórica em pesquisas em contabilidade, o que não aconteceu nos achados desta pesquisa.

\subsubsection{Paradigmas de Pesquisa}

Burrell e Morgan (1979) explicam que os paradigmas são mutuamente excludentes, ou seja, cada artigo pode ser classificado em apenas um dos paradigmas, já que estes possuem perspectivas próprias. O Quadro 10 relata os tipos de paradigmas de pesquisa utilizados pelos artigos publicados nos periódicos.

\begin{tabular}{|c|c|c|}
\hline \multirow{2}{*}{ Quadro 10: Paradigmas de pesquis } & \multicolumn{2}{|c|}{ Paradigmas de Pesquisa } \\
\hline & Funcionalista & Interpretativo \\
\hline $\begin{array}{l}31 \text { Artigos publicados em periódicos } \\
\text { internacionais }\end{array}$ & $93,5 \%$ & $6,5 \%$ \\
\hline $\begin{array}{l}3 \text { Artigos publicados em periódicos } \\
\text { nacionais }\end{array}$ & $100 \%$ & $0 \%$ \\
\hline 34 Artigos publicados em periódicos & $94,1 \%$ & $5,9 \%$ \\
\hline
\end{tabular}

Fonte: Dados da pesquisa

Observa-se que a maioria dos artigos possui foco na geração de conhecimento, com o intuito de solucionar problemas práticos das organizações. Não foram encontrados trabalho embasado nos paradigmas Estruturalismo Radical e Humanismo Radical.

Estes achados corroboram com outros trabalhos. Nascimento, Junqueira e Martins (2010) realizaram pesquisa que teve como objetivo identificar e analisar as características epistemológicas da produção acadêmica da pesquisa em contabilidade gerencial no Brasil. Ao todo, os autores analisaram 287 trabalhos, e constataram que 97\% dos trabalhos abordam a perspectiva funcionalista. Comparando com a área da administração, outros trabalhos apontaram a predominância de pesquisas funcionalistas (MACHADO-DA-SILVA; CUNHA; ANBONI, 1990; VERGARA, 2005; BERTERO; CALDAS; WOOD, 2005).

\section{Considerações Finais}

Este trabalho teve o objetivo de identificar o perfil da produção científica, no Brasil e internacionalmente, acerca da GCI, além de realizar a análise de conteúdo e epistemológica dos artigos publicados em periódicos.

O tema apresentou baixa quantidade de trabalhos publicados (55 trabalhos), e uma baixa quantidade de autores que publicaram (73 autores), sendo que 28 são nacionais e 45 internacionais. Não se observou publicações realizadas entre autores brasileiros e autores de outros países, e também se constatou baixa interação entre as redes e o isolamento de alguns autores nacionais e também estrangeiros. Os primeiros trabalhos identificados são da década de 1990, mantendo um número pequeno de publicações até a década de 2000, e então, a partir de 2010 as publicações passaram a ser mais constantes e em maior número.

Quanto às publicações nacionais, tiveram início no ano de 2007. A produção nacional é pequena (22 trabalhos, sendo 12 em eventos), mas emergente (13 trabalhos nos últimos 3 
anos). Observa-se que no cenário brasileiro há uma tendência de crescimento nas pesquisas sobre GCI, corroborando as conclusões da pesquisa de Faria et al. (2010). Os congressos desempenharam um importante papel na difusão dos trabalhos sobre a GCI, destacando o Congresso Brasileiro de Custos (cinco trabalhos) e o Congresso USP de Controladoria e Finanças (três trabalhos).

Quanto ao cenário internacional, representado, segundo os parâmetros desta pesquisa, por artigos publicados em periódicos (31) e livros (2), o Management Accounting Research destaca-se como o periódico internacional que mais publicou trabalhos sobre GCI, corroborando com os achados de Faria et al. (2010). Destaca-se ainda a heterogeneidade dos periódicos que publicaram acerca do tema.

Robin Cooper, por meio de seus artigos publicados em 1994 (COOPER; YOSHIKAWA, 1994a; COOPER; YOSHIKAWA, 1994b; COOPER, 1994) fortaleceu o termo Interorganizational Cost Management. Posteriormente, em 1999 com a publicação do primeiro livro específico sobre o assunto, juntamente com Regine Slagmulder, ajudaram a organizar e criar ideias e conceitos acerca do tema (COOPER; SLAGMULDER, 1999).

Sociogramas demonstraram as relações existentes entre os autores dos trabalhos, evidenciando a não ocorrência de relações entre os autores brasileiros e internacionais, e poucas redes entre os autores, de um modo geral.

Referindo-se à análise epistemológica dos artigos publicados em periódicos, constatou-se que, na plataforma teórica dos artigos, há predominância na citação de artigos publicados em periódicos. Entretanto, muitos trabalhos utilizaram os livros como principal fonte de pesquisa para a elaboração dos estudos, porém, muitas vezes os livros são escritos de maneira normativa, sem apresentar estudos que relatem os conceitos na prática.

Quanto às estratégias metodológicas dos trabalhos, os estudos de campo são os mais expressivos. Foram utilizados principalmente como estudos de caso, onde os pesquisadores buscaram compreender a realidade das empresas, com o intuito criar conhecimento corrobora com os achados de Nascimento, Junqueira e Martins (2010) e Hesford et al. (2007), que conduziram estudos bibliométricos no campo da contabilidade gerencial. Destaca-se o setor automotivo e o Japão como cenários das pesquisas.

Nas pesquisas de campo observadas, foram identificados problemas citados por Theóphilo e Iudícibus (2005). Nesta pesquisa os autores observaram que muitos trabalhos configuram-se apenas como meras demonstrações das práticas das empresas, sem apresentar o rigor e profundidade que este tipo de pesquisa exige, ou seja, sem apresentar protocolos, validação e imersão nos dados.

A maioria dos trabalhos não aborda uma teoria que explica a realidade, fato que corrobora com os achados de Theóphilo e Iudícibus (2005) e Nascimento, Junqueira e Martins (2010). A maior parte dos trabalhos analisados utilizou conceitos como plano de fundo para desenvolver as pesquisas, citando achados e modelos postulados pela literatura acerca da GCI.

Observa-se que a maioria dos artigos possui foco na geração de conhecimento, com o intuito de solucionar problemas práticos das organizações. Não foram encontrados trabalho embasado nos paradigmas Estruturalismo Radical e Paradigma Humanismo Radical. Estes achados corroboram com outros trabalhos (NASCIMENTO, JUNQUEIRA, MARTINS, 2010; MACHADO-DA-SILVA; CUNHA; ANBONI, 1990; VERGARA, 2005; BERTERO; CALDAS; WOOD, 2005).

Dentre os artigos publicados em periódicos acerca da GCI, os temas mais recorrentes foram a relação entre o Open Book Accounting e GCI, e relação entre fornecedores e clientes. Esse fato corrobora com a literatura, ao passo que ressalta a importância do compartilhamento de informações e gestão dos relacionamentos.

Por fim, observou-se pequeno número de estudos que aplicam os conceitos da Gestão de Custos Interorganizacionais no cenário brasileiro, sendo uma lacuna do conhecimento, já 
que é importante respeitar as idiossincrasias das empresas e da cultura nacional. O trabalho contribui ao passo que demonstra a o cenário das publicações acerca da GCI, além de discutir as questões epistemológicas dos artigos publicados em periódicos.

Como recomendação para trabalhos futuros, é sugerido o desenvolvimento de pesquisas que avaliem a aplicabilidade da GCI em empresas brasileiras. Outra questão relevante seria a realização de um levantamento de opinião dos gestores com o intuito de entender se estes aceitariam adotar as práticas que a literatura da GCI considera como necessárias para o sucesso de sua aplicação, como por exemplo, a utilização da Contabilidade de Livro Aberto e a disponibilidade de orçamentos detalhados entre os membros da cadeia de suprimento. Além disso, o desenvolvimento de um modelo que auxiliasse o gestor, numa dinâmica de passo a passo, a avaliar se no cenário em que sua empresa está inserida há fatores que incentivam ou inibem a execução de ações coordenadas entre os membros da cadeia. A elucidação dessas questões ajudaria a entender quais fatores coíbem ou incentivam a aplicação da GCI no cenário brasileiro.

\section{Referências}

ABBADE, E. B. Cooperação Interorganizacional na Associação Londrinense de Empresários Supermercadistas e no APL têxtil de Goioerê: uma análise sob a ótica da teoria dos custos de transação. 2005. 149 f. Dissertação (Mestrado em Administração) - Setor de Ciências Sociais e Aplicadas, Universidade Federal do Paraná, Curitiba, 2005.

AGNDAL, H.; NILSSON, U. Different Open Book Accounting practices for different purchasing strategies. Management Accounting Research, v. 21, n. 3, p. 147-166, 2010.

AGNDAL, H.; NILSSON, U. Interorganizational Cost Management in the exchange process. Management Accounting Research, London, v. 20, n. 1, p. 85-101, 2009.

AGNDAL, H.; NILSSON, U. Supply chain decision-makings up ported by an open books policy. International Journal of Production Economics, v. 116, n. 1, p.154-167, 2008.

AGUIAR, A. B. de; ROCHA, W. Uma Análise da Complementaridade Entre Gestão Interorganizacional de Custos e Open Book Accounting. In: CONGRESSO DE CONTROLADORIA E FINANÇAS, 7, 2007, São Paulo. Anais... São Paulo: USP, 2007. CD-ROM.

AMATO NETO, J. Redes de cooperação produtiva e clusters regionais: oportunidades para as pequenas e médias empresas. 1. ed. São Paulo: Atlas, 2000. 168 p.

ARAÚJO, C. A. Bibliometria: evolução histórica e questões atuais. Em Questão, Porto Alegre, v. 12, n. 1, p. 11-32, 2006.

BASTL, M.; GRUBIC, T.; TEMPLAR, S.; HARRISON, A.; FAN, I. Inter-organisational costing approaches: the inhibiting factors. The International Journal of Logistics Management, v. 21, n. 1, p. 65-88, 2010.

BAXTER, J.; CHUA, W. F. Alternative management accounting research whence and whither. Accounting, Organizations and Society, v. 28, n. 2/3, p. 97-126, 2003. 
BERTERO, C. O.; CALDAS, M. P.; WOOD T. Produção científica em administração no Brasil: o estado da arte. 1. ed. São Paulo: Atlas, 2005. 170 p.

BRAGA, A.; SOUZA, M. A. de; KRONBAUER, C. A.; BRAGA, D. G. Mapeamento da Gestão de Custos Interorganizacionais: uma metanálise envolvendo pesquisadores, métodos e discussões. In: CONGRESSO ANPCONT, 6., 2012, Florianópolis. Anais... Florianópolis: ANPCONT, 2012. CD-ROM.

BURNS, T.; STALKER, G. M. The management of innovation. 1. ed. Londres: Tavistock, 1961. 269 p.

BURRELL, G.; MORGAN G. Sociological Paradigms and Organizational Analysis. 1. ed. London: Heinemann Educational Books, 1979. 427 p.

CAMACHO, R. R. Fatores condicionantes da Gestão de Custos Interorganizacionais na cadeia de valor de hospitais privados no Brasil: uma abordagem a luz da teoria da contingência. 2010. 216 f. Tese (Doutorado em Ciências Contábeis) - Faculdade de Economia, Administração e Contabilidade, Universidade de São Paulo, São Paulo, 2010.

CARVAlHO, M. C. de. Construindo o saber: técnicas de metodologia científica. 1. ed. São Paulo: Papirus, 1988. 180 p.

COAD, A.; CULLEN, J. Inter-organisational Cost Management: towards on evolutionary perspective. Management Accounting Research, v. 17, n. 4, p. 342-369, 2006.

COAD, A.; SCAPENS, B. Inter-organizational Cost Management. Financial Management, p. 38-39, 2006.

COOPER, D.; HOPPER, T. Critical theorising in management accounting research. Handbook of management accounting research, v. 1, p. 207-245, 2006.

COOPER, R. Japanese cost management practices. CMA Magazine, v. 68, n. 8, p. 20-25, 1994.

COOPER, R.; SLAGMULDER, R. Cost Management beyond the Boundaries of the firm. Management Accounting, v. 79, n. 9, p. 18-20, 1998.

COOPER, R.; SLAGMULDER, R. Interorganizational Cost Management and relational context. Accounting Organizations and Society, v. 29, n. 1, p. 1-26, 2004.

COOPER, R.; SLAGMULDER, R. Interorganizational costing, Part 1. Cost Management, v. 17, n. 5, p. 14-21, 2003a.

COOPER, R.; SLAGMULDER, R. Interorganizational costing, Part 2. Cost Management, v. 17, n. 6, p. 12-24, 2003 b.

COOPER, R.; SLAGMULDER, R. Supply chain development for the lean enterprise: Interorganizational Cost Management. 1. ed. New Jersey: The IMA Foundation for Applied Research, 1999. 544 p. 
COOPER, R.; YOSHIKAWA, T. Inter-organizational Cost Management systems: the case of the Tokyo-Yokohama-Kamakura supplier chain. International Journal of Production Economics, Amsterdam, v. 37, n. 1, p. 51-62, 1994a.

COOPER, R.; YOSHIKAWA, Takeo. Kamakura Ironworks Co. Ltd. Harvard Business School Cases, Boston: Case Study 9-195-054,1994b.

CORRÊA, H. L. Administração de cadeias de suprimento e logística: o essencial. 1. ed. São Paulo: Atlas, 2014. 264 p.

CULLEN, J. Supply chain accounting. Financial management, p. 27, 2006.

DANIELS, B. Integration of the supply chain for total through-cost reduction. Total Quality Management, v. 10, n. 4/5, p. 481-490, 1999.

DEKKER, H. Control of inter-organizational relationships, evidence on appropriation concerns and coordination requirements. Accounting Organizations and Society, v. 29, n. 1, p. $27-49,2004$.

DEKKER, H. Value chain analysis in interfirm relationships: a field study. Management Accounting Research, v. 14, n. 1, p. 1-23, 2003.

DIAS, T.; BIROCHI, R.; DEAMBROSIS, A. M.; DAROSI, G. C. M.; MATOS, O. A. A Construção do Conhecimento sobre Estratégia: uma análise da produção científica recente (2003-2011), na perspectiva de Burrel e Morgan. In: ENCONTRO DE ENSINO E PESQUISA EM ADMINISTRAÇÃO E CONTABILIDADE - ENEPQ, 4, 2013, Brasília. Anais... Brasília: ANPAD, 2013. CD-ROM.

DUBOIS, A. Strategic Cost Management across Boundaries of Firms. Industrial Marketing Management, v. 2, n. 5, p. 365-374, 2003.

FACCI, N. Um estudo sobre as características dos fatores contingenciais na Gestão de Custos Interorganizacionais em um arranjo produtivo local do setor de tecnologia da informação na região noroeste do Paraná. 2011. 106 f. Dissertação (Mestrado em Contabilidade) - Setor de Ciências Sociais Aplicadas, Universidade Federal do Paraná, Curitiba, 2011.

FARIA, A. C. de; PEREIRA, A. N.; SOUZA, B. C. de; SOARES, I. C. Gestão de Custos Interorganizacionais (GCI) e Contabilidade de Livros Abertos (CLA): Investigação bibliométrica com ênfase em periódicos internacionais e nacionais. In: CONGRESSO BRASILEIRO DE CUSTOS, 17, 2010, Belo Horizonte. Anais... Belo Horizonte, 2010. CDROM.

FARIA, A. C.; SOARES, I. C.; ROCHA, W.; ROSSI, G. B. A prática da Gestão de Custos Interorganizacionais em uma montadora de veículos na região do Grande ABC. Revista Brasileira de Gestão de Negócios, v. 15, n. 49, p. 617-638, 2013.

FAYARD, D.; LEE, L.; LEITCH, R.; KETTINGER, W. Effect of internal cost management, information systems integration, and absorptive capacity on Inter-organizational Cost 
Management in supply chains. Accounting, Organizations and Society, v. 37, n. 3, p. 168187, 2012.

GANGOPADHYAY, A.; HUANG, Z. Studying the Value of Information Sharing in EBusiness Supply Chain Management. Journal of International Technology and Information Management, v. 13, n. 1, p. 49-60, 2004.

GARCIAS, P. M. Alianças Estratégicas e Coordenação no Agrobusines. 1999. 134 f. Tese (Doutorado) - Departamento de Economia, Universidade de São Paulo, São Paulo, 1999.

GIL, A. C. Métodos e técnicas de pesquisa social. 5. ed. São Paulo: Atlas, 1999. 206 p.

GONSALVES, E. P. Iniciação à Pesquisa Científica. 3. ed. São Paulo: Alínea, 2003. 80 p.

HAIR JR, J.; BABIN, B.; MONEY, A.; SAMOUEL, P. Fundamentos de métodos de pesquisa em administração. 1. ed. São Paulo: Bookman, 2005. 471 p.

HESFORD, J.; LEE, S.; STEDE, W. V.; YOUNG, M. Management Accounting: A bibliographic study. Handbook of Management Accounting Research, v. 1, p. 3-26, 2007.

HOFFJAN, A.; KRUSE, H. Open Book Accounting in supply chain: when and how is it used in practice? Cost Management, v. 20, n. 6, p. 40-47, 2006.

HOFFJAN, A.; LÜHRS, S.; KOLBURG, A. Cost Transparency in supply chains: demystification of the cooperation tenet. Schmalenbach Business Review, v. 63, n. 3, p. 230251, 2011.

JONES, M. J.; SHOEMAKER, P. Accounting narratives: a review of empirical studies of content and readability. Journal of Accounting Literature, Gainesville, v. 13, n. 1, p. 142$182,1994$.

KAJÜTER, P.; KULMALA, H. Open Book Accounting in networks: Potential achievements and reasons for failures. Management Accounting Research, v. 16, n. 2, p. 179-204, 2005.

KERLINGER, F. Metodologia da pesquisa em ciências sociais: um tratamento conceitual 1. ed. São Paulo: EPU/EDUSP, 1991. 378 p.

KIDDER, L. Métodos de pesquisa nas relações sociais. 2. ed. São Paulo: EPU, 1987. 133 p.

KIM, K. K.; PARK, S.; RYOO, S. Y.; PARK, S. K. Inter-organizational cooperation in buyer-supplier relationships: Both perspectives. Journal of Business Research, v. 63, n. 8, p. 863-869, 2010.

KULMALA, H.; KAJÜTER, P.; VALKOKARIA, K. Inter-organizational Cost Management in SME networks. In: MANUFACTURING ACCOUNTING RESEARCH, COST AND PERFORMANCE MANAGEMENT IN SERVICES AND OPERATIONS, 8., 2007, Trento. Anais... Trento: EIASM, 2007.

KULMALA, H.; PARANKO, J.; UUSI-RAUVA, E. The role of cost management in network relationships. International Journal of Production Economics, v. 79, n. 1, p. 33-43, 2002. 
KUMRA, R.; AGNDAL, H.; NILSSON, U. Open book practices in buyer-supplier relationships in India. Journal of Business and Industrial Marketing, v. 27, n. 3, p. 196$210,2012$.

LAMBERT, D.; COOPER, M. Issues in supply chain management. Industrial Marketing Management, v. 29, n. 2, p. 65-83, 2000.

LUO, Y. Antecedents and consequences of personal attachment in cross-cultural cooperative ventures. Administrative Science Quarterly, v. 46, n. 2, p. 177-201, 2001.

MACHADO-DA-SILVA, C.; CUNHA, V.; ANBONI, N. Organizações: o estado da arte da produção acadêmica do Brasil. In: ENCONTRO NACIONAL DA ASSOCIAÇÃO NACIONAL DE PÓS-GRADUAÇÃO E PESQUISA EM ADMINISTRAÇÃO ENANPAD, 14., 1990, Florianópolis. Anais... Florianópolis: ANPAD, 1990. Organizações, p.11-28.

MARCONI, M. de A.; LAKATOS, E. M. Técnicas de pesquisa. 7. ed. São Paulo: Atlas, 2008. 277p.

MARTINS, G. de A.; BERNADELLI, R. Plataforma teórica - trabalhos dos $3^{\circ}$ e $4^{\circ}$ congressos USP de controladoria e contabilidade: um estudo bibliométrico. In: CONGRESSO DE CONTROLADORIA E FINANÇAS, 5., 2005, São Paulo. Anais... São Paulo: USP, 2005. CD-ROM.

MARTINS, G. de A.; THEÓPHILO, C. R. Metodologia da investigação científica para ciências sociais aplicadas. 2. ed. São Paulo: Atlas, 2009. 264 p.

MATTAR, F. N. Pesquisa de Marketing: metodologia, planejamento, execução, análise. 3. ed. São Paulo: Atlas, 1996. 270 p.

MEIRELLES, A. de M.; GONÇALVES, C. A. Uma abordagem multiparadigmática para a disciplina estratégia. In: ENCONTRO DE ESTUDOS EM ESTRATÉGIA (3ES), ASSOCIAÇÃO NACIONAL DE PÓS-GRADUAÇÃO E PESQUISA EM ADMINISTRAÇÃO - ANPAD, 2., 2005, Rio de Janeiro. Anais... Rio de Janeiro: ANPAD, 2005. CD-ROM

MILLER, P. Management accounting and sociology. Handbook of management accounting research, Amsterdam, v. 1, p. 285-295, 2007.

MÖLLER, K.; WINDOLPH, M. OBA, IOCM and the impact on supplier relationship satisfaction Inter-organisation. Financial Management, n. 10, p. 54-56, 2012.

MÖLLER, K.; WINDOLPH, M.; ISBRUCH, F. The effect of rational factors on Open Book Accounting and Inter-organisational Cost Management in buyer-supplier partnerships. Journal of Purchasing \& Supply Management, v. 17, n. 2, p.121-131, 2011.

MOURITSEN, J.; HANSEN, A.; HANSEN, C. Ø. Inter-organizational controls and organizational competencies: Episodes around target cost management/functional analysis 
and Open Book Accounting. Management Accounting Research, v. 12, n. 4, p. 221-244, 2001.

MUNDAY, M. Accounting cost data disclosure and buyer-supplier partnerships: A research note. Management Accounting Research, v. 3, n. 3, p. 245-250, 1992.

NASCIMENTO, A. R. do; JUNQUEIRA, E.; MARTINS, G. de A. Pesquisa acadêmica em contabilidade gerencial no Brasil: análise e reflexões sobre teorias, metodologias e paradigmas. Revista de Administração Contemporânea, Curitiba, v. 14, n. 6, p. 1113-1133, 2010.

NASCIMENTO, S. do; PEREIRA, A. M.; SCARPIN, J. E. Os fatores condicionantes da Gestão de Custos Interorganizacionais em uma indústria metalúrgica da cidade de Rio do Sul - SC. ABCustos, São Leopoldo, v. 7, n. 2, p. 1-22, 2012.

NOREK, C.; POHLEN, T. Cost knowledge: a foundation for improving supply chain relationships. International Journal of Logistics Management, v. 12, n. 1, p. 37-51, 2001.

OLIVEIRA, S. L. Tratado de Metodologia Científica: projetos de pesquisa, TGI, TCC, monografias, dissertações e teses. 1. ed. São Paulo: Pioneira Thomson learning, 2004. 320 p.

PARASURAMAN, A. Marketing research. 2. ed. New York: Addison Wesley, 1991. 898 p.

PFEFFER, J.; SALANCIK, G. The external control of organizations: A resource dependence perspective. 1. ed. New York: Harper \& Row, 1978. 336 p.

PORTER, M. Estratégia competitiva: técnicas para análise de indústria e da concorrência. 2. ed. Rio de Janeiro: Campus, 2004. 409 p.

PORTER, M. Vantagem competitiva: criando e sustentando um desempenho superior. 18. ed. Rio de Janeiro: Campus, 1989. 512 p.

SEURING, S.; GOLDBACH, M. Cost management in supply chains. 1. ed. New York: Springer, 2002. $447 \mathrm{p}$.

SHANK, J.; GOVINDARAJAN, V. Strategic cost management: the new tool for competitive advantage. 1. ed. New York: Free Press, 1993. 694 p.

SMITH, M. Research Methods in Accounting. 1. ed. New Delhi: Sage Publications, 2003. $224 \mathrm{p}$.

SOUZA, B. C. de; ROCHA, W. GCI - Gestão de Custos Interorganizacionais: Gerenciamento de resultados entre organizações distintas por meio de ações coordenadas. 1. ed. São Paulo: Atlas, 2009. 130 p.

SUTTON, R.; STAW, B. What theory is not? Administrative Science Quarterly, v. 40, n. 3, p. 371-384, 1995.

THEÓPHILO, C. R.; IUDÍCIBUS, Sérgio. Uma análise crítico-epistemológica da produção científica em Contabilidade no Brasil. UnB Contábil, v. 8, n. 2, p. 147-175, 2005. 
THUMS, Jorge. Acesso à Realidade. 3. ed. São Paulo: Ulbra, 2003. 232 p

UZZI, B. The sources and consequences of embeddedness for the economic performance of organizations: the network effect. American Sociological Review, v. 61, n. 4, p. 674-698, 1996.

VERGARA, S.ylvia C. Métodos de pesquisa em administração. 1. ed. São Paulo: Atlas, 2005. $288 \mathrm{p}$.

VISKARI, S.; KÄRRI, T. A model for working capital management in the interorganisational context. International Journal of Integrated Supply Management, v. 7, n. 1/2/3, p. 61-79, 2012.

WEIERS, R. Marketing Research. 2 ed. New York: Prentice Hall, 1988. 688 p.

WILLIAMSON, O. Las Instituciones Económicas del Capitalismo. Tradução de Eduardo Suarez. 1. ed. México: Fondo de Cultura Económica, 1989. 435 p.

WINDOLPH, M.; MOELLER, Klaus. Open Book Accounting: Reason for failure of interfirm cooperation? Management Accounting Research, Amsterdam, v. 23, n. 1, p. 47-60, 2012.

YIN, R. Estudo de caso: planejamento e métodos. 2. ed. Porto Alegre: Bookman, 2001. 205 p.

ZIKMUND, W. Business Research Methods. 5. ed. Orlando: Dryden, 1997. 829 p. 